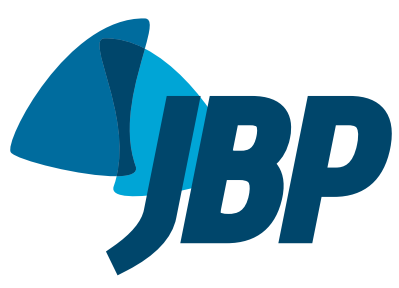

1. Ambulatório de Auxílio ao Abandono do Tabagismo, Hospital São Lucas, Faculdade de Medicina, Pontifícia Universidade Católica do Rio Grande do Sul - PUCRS - Porto Alegre (RS) Brasil.

2. Faculdades Integradas de Taquara FACCAT - Taquara (RS) Brasil.

3. Departamento de Medicina Interna e Pneumologia, Faculdade de Medicina, Pontifícia Universidade Católica do Rio Grande do Sul - PUCRS - Porto Alegre (RS) Brasil.

a. (ID) http://orcid.org/0000-0002-2546-2987

b. (iD http://orcid.org/0000-0002-4343-025X

Submitted: 10 January 2018

Accepted: 18 April 2018

Study carried out in the Ambulatório de Auxílio ao Abandono do Tabagismo, Hospital São Lucas, Faculdade de Medicina, Pontifícia Universidade Católica do Rio Grande do Sul - PUCRS - Porto Alegre (RS) Brasil.

\section{Does everyone who quit smoking gain weight? A real-world prospective cohort study}

\author{
Edna Jeremias-Martins ${ }^{1,2, a}$, José Miguel Chatkin ${ }^{1,3, b}$
}

\begin{abstract}
Objective: To evaluate weight changes after 12 months of biochemically confirmed smoking abstinence, comparing patients who lost weight or maintained their baseline weight with those who gained weight. Methods: This was a real-world prospective cohort study conducted at the Outpatient Smoking Cessation Clinic of São Lucas Hospital, in the city of Porto Alegre, Brazil, between 2010 and 2016. The patients evaluated received intensive smoking cessation counseling, focused especially on weight issues, together with pharmacotherapy, and were followed for 12 months. The baseline and final weights were measured. Continuous abstinence was confirmed by determining the concentration of exhaled carbon monoxide (eCO). Results: Of a total of 348 patients evaluated, 161 $(46.2 \%)$ achieved continuous abstinence (eCO < 10 ppm) over the 12-month follow-up period. Of those 161 patients, 104 (64.6\%) maintained their initial weight or had a weight change of no more than $5 \%$ in relation to their baseline weight, whereas the remaining $57(35.4 \%)$ had a weight gain of more than $5 \%, 18$ of those patients showing a $>10 \%$ increase over their baseline weight. The number needed to harm (i.e., the number of patients required in order to detect one patient with a weight increase) was calculated to be 3.6 (95\% Cl: 2.8-5.4). Conclusions: Weight gain is not necessarily associated with smoking cessation, and smokers who are motivated to quit should be informed of that fact. This information could also be useful for addressing smokers who are still undecided because of possibility of weight gain.
\end{abstract}

Keywords: Weight loss; Smoking cessation; Tobacco smoking; Treatment outcome.

\section{INTRODUCTION}

Cigarette smoking continues to be the leading preventable cause of death in most countries. ${ }^{(1)}$ It is associated with high morbidity rates and generates significantly high financial costs for the health care system. (2) Promoting smoking cessation is an important strategy to reduce the morbidity and mortality associated with smoking-related diseases. In Brazil, smoking is also a major public health problem, although there is a major trend toward a decrease in the proportion of smokers. Recent data show that the prevalence of smoking among individuals $\geq 18$ years of age decreased from $15.6 \%$ in 2006 to $10.8 \%$ in 2015 ( $p<0.05$ ), corresponding to a $30.7 \%$ reduction. $^{(3)}$

The inverse relationship between body weight and smoking is well recognized. ${ }^{(4-6)}$ Smokers typically have a lower body weight than do nonsmokers. ${ }^{(7,8)}$ Reduced food intake in smokers has been attributed to various mechanisms $(7,9,10)$ : increased stimulation of the adrenergic system; lipolysis and thermogenesis secondary to an increased basal metabolic rate; increased energy expenditure; and nicotine-induced appetite suppression. There is also evidence that some additives employed in the industrial production of the cigarettes are appetite suppressants, such as tartaric acid and 2-acetylpyridine..$^{(11)}$ Conversely, smoking cessation is associated with weight gain,(10) and former smokers usually weigh more than do current smokers and never smokers. ${ }^{(5,12-14)}$ When an individual quits smoking, the aforementioned mechanisms cease to operate, leading to an increase in body weight. A low socioeconomic status (SES) is also a contributing factor for weight gain. Currently, most smokers belong to a lower SES, engage in less physical activity, and have a high-calorie/high-fat diet. The increase in caloric intake is probably responsible for the greater proportional weight gain seen during the first 3 months after smoking cessation. ${ }^{(10)}$ In addition, former smokers seek oral rewards through the consumption of foods with high sugar and fat content. There is also a rapid recovery of the senses of smell and taste, which encourages food intake. ${ }^{(11)}$

There is evidence that a considerable proportion of smokers gain weight when they quit smoking. ${ }^{(8,15-17)}$ Approximately $50 \%$ of women and $26 \%$ of men state that their main concern in quitting smoking is weight gain, which is also a major risk factor for relapse. ${ }^{(18)}$ The significant proportion of former smokers who maintain their original weight or show no more than $5 \%$ variation in relation to their baseline weight is not usually emphasized during the counseling of smokers who are about to initiate an attempt to stop smoking.

The aim of this study was to assess weight changes during the smoking cessation process and to identify the factors involved in such changes. We had a special

Correspondence to:

José Miguel Chatkin. Hospital São Lucas, PUCRS, Avenida Ipiranga, 6690, sala 501, CEP 90610-000, Porto Alegre, RS, Brasil.

Tel.: 5551 3320-3378. Fax: 5551 3320-3316. E-mail: jmchatkin@pucrs.br

Financial support: None. 
interest in the subgroup of patients that maintained their weight or showed a variation of no more than $5 \%$ in relation to their baseline weight. ${ }^{(19)}$ We also calculated the number needed to harm (NNH), which, for the purposes of the present study, was the number of patients required in order to identify one patient with a clinically relevant weight gain in relation to the baseline weight among the smokers who succeeded in quitting smoking.

\section{METHODS}

This was a prospective cohort study of smokers who sought treatment at the Outpatient Smoking Cessation Clinic of Hospital São Lucas da Pontifícia Universidade Católica do Rio Grande do Sul (HSL-PUCRS, São Lucas Hospital of the Pontifical Catholic University of Rio Grande do Sul), in the city of Porto Alegre, Brazil. The screening period was from June 2010 to June 2016.

The inclusion criteria were being a current smoker, having $a \geq 10$ pack-year smoking history, being motivated to quit smoking, and not having been under treatment for smoking cessation in the last 6 months. The exclusion criteria were having a severe clinical or psychiatric illness, including self-reported alcohol or illicit drug abuse, as well as being illiterate, being pregnant, and breastfeeding.

The study was approved by the HSL-PUCRS Scientific and Ethics Committee and is in compliance with the Brazilian regulatory guidelines for research involving human beings (National Health Council Resolution no. 466/12). All participants gave written informed consent.

The HSL-PUCRS smoking cessation program is a 12-month program and is representative of the daily clinical practice in smoking cessation treatment in Brazil. The physicians involved in the study were responsible for allocating the patients to each of the pharmacological treatment arms of the study: no pharmacological treatment, bupropion, nortriptyline, nicotine replacement therapy, and varenicline. To that end, the physicians considered the level of nicotine dependence, as determined with the Fagerström Test for Nicotine Dependence (FTND); tolerance to drugs in any previous smoking cessation treatments; patient preference for a given drug; and the financial ability of the patient to acquire the medication proposed, given that patients did not receive the medications for free. All patients received the same regimen of counseling. The program consisted of an initial medical interview, in which the patient completed a standardized questionnaire on smoking history and the level of motivation to quit. The physician then augmented the records with data regarding the general medical history, physical examination findings, baseline body weight, respiratory symptoms, and use of medications for the treatment of comorbidities. The level of nicotine dependence was then assessed with the FTND, which classifies it as low (FTND score $\leq 3$ ), medium (FTND score of $4-7$ ), or high (FTND score $\geq 8$ ). ${ }^{(20)}$ The concentration of exhaled carbon monoxide (eCO) was measured with a portable monoximeter (MicroCO; Micro Medical Limited, Rochester, England). Finally, the patient, the physician, and a nurse collectively agreed upon a quit day, typically scheduled for 8-9 days after the initial assessment. During the first three months of treatment, the patients attended individual treatment sessions, 15 days apart, all conducted by the same physician. After this initial period, the patients returned once a month until completing 12 months of abstinence. At all visits, the patients reported on their smoking habits and the eCO level was determined in order to confirm the smoking status. There were also visits with a trained nurse, specifically related to preventing weight change and developing strategies to cope with this problem. Withdrawal symptoms were also fully discussed in all sessions. The last follow-up visit was at 12 months of continuous abstinence, at which point the final weight was recorded. Body weight was always determined with the same scale (Filizola eletrônica digital; Industria Filizola, São Paulo, Brazil), calibrated as recommended by the manufacturer.

Successful treatment was defined as continuous abstinence (eCO $<10 \mathrm{ppm}$ at all visits). Subjects who discontinued treatment or were lost to follow-up were classified as cases of treatment failure and were not included in the analysis. Any patient who did not attend a scheduled appointment received a phone call from the outpatient clinic, as a routine procedure.

For assessing outcomes, we stratified the patients into two groups, according to changes in body weight: NoChange (weight unchanged or variation of no more than $5 \%$ in relation to the baseline weight); and Change (weight gain of more than $5 \%$ ). Variations in body weight greater than $5 \%$ were considered clinically relevant. ${ }^{(19)}$

We described continuous variables as means \pm standard deviations when the data distribution was normal and as medians and interquartile ranges when it was not. We described categorical variables as absolute and relative frequencies. We used the Student's t-test to compare means and the nonparametric MannWhitney test to compare medians. For categorical data comparisons, we used the chi-square test or Fisher's exact test.

To evaluate weight change during the follow-up period, we used a Poisson regression model with a robust standard error to estimate relative risk, calculating the corresponding 95\% confidence intervals and adjusting for several potential confounders. In addition, to determine the magnitude of the impact that smoking cessation had on weight gain, we calculated the $\mathrm{NNH}$ and the corresponding 95\% confidence interval. The level of significance was set at $p<0.05$. Data were analyzed with the SPSS Statistics software package, version 21.0 (IBM Corp., Armonk, NY, USA).

\section{RESULTS}

We screened 450 smokers, of whom 102 were excluded (Figure 1). Therefore, the final study sample 
comprised 348 patients, 161 (46.3\%) of whom were abstinent throughout the 12-month follow-up period (Figure 1).

Table 1 shows the characteristics of the patients evaluated, by outcome (success vs. failure in quitting smoking) and weight-change group (NoChange vs. Change). To maintain the numbers of patients in both groups, we used a cut-off age of 50 years, rather than the traditional 60 years. The cut-off age of 50 years has been used previously. ${ }^{(21)}$ Among the 161 patients in whom the treatment was successful, 104 (64.6\%) were in the NoChange group and 57 (35.4\%) were in the Change group. Among the 187 patients in whom the treatment failed, 172 (92.0\%) were in the NoChange group and $15(8.0 \%)$ were in the Change group.

Among the patients in whom the treatment was successful, the baseline body weight was higher in the NoChange group patients than in the Change group patients, there being, as expected, less weight gain in the former group ( $p<0.001$ for both). In general, there was a weak correlation between being younger and being in the NoChange group $(p=0.058)$. Among the patients in whom the treatment failed, those in the NoChange group were significantly younger than were those in the Change group, as well as showing significantly less weight gain ( $p=0.05$ for both). We found no significant differences between the two groups regarding any of the other characteristics evaluated. As can be seen in Table 2, the patients were also grouped into seven categories, according to the percent weight change in relation to the baseline weight. Table 2 also shows the distribution of the percent weight change from the baseline weight by outcome. We detected significant differences between the two outcomes only for categories 3, 4, 6, and 7 .

Table 3 demonstrates the risk factors for Change group patients, in univariate analysis and multivariate Poisson regression (adjusted for gender, age, level of nicotine dependence, pharmacological treatment received, number of clinical visits attended, and baseline body weight). None of the factors evaluated were found to confer significant risk for or protection against a > 5\% weight gain in relation to the baseline weight. Figure 2 shows the risk and protective factors in a forest plot. The NNH for a $>5 \%$ weight gain in relation to the baseline weight was 3.6 (95\% CI: 2.8-5.4).

\section{DISCUSSION}

In this study, the majority of the patients who achieved continuous smoking abstinence after quitting smoking had no significant weight changes or maintained their initial weight. Although many smokers gain weight after quitting smoking, the weight gain is usually minimal, ${ }^{(5,12,22)}$ as we found in our sample. Therefore, the widespread notion in the lay population and among some health professionals that smoking cessation is necessarily associated with weight gain is not entirely true.

Aubin et al. ${ }^{(12)}$ found that quitting smoking was associated with a mean weight gain of $4.7 \mathrm{~kg}$ at 12 months after smoking cessation, $13 \%$ of the abstinent smokers having gained more than $10 \mathrm{~kg}$. However, a significant proportion of the former smokers evaluated in that study actually lost weight. Tian et al. ${ }^{(23)}$ assessed data from 63,403 individuals who quit smoking, evaluating 388,432 current smokers as a control group. The former smokers had a mean weight gain of $4.10 \mathrm{~kg}$ (95\% CI: 2.69-5.51), which was significantly greater than that observed in the current smokers $(p<0.001)$.

Of the 187 patients in whom the treatment failed in the present study, $172(92.0 \%)$ patients had a weight change $<5 \%$ in relation to the baseline weight The lack of relevant changes in this group might be related to the attempt to quit smoking or to the natural weight variation of the subjects during the study period.

Our findings are consistent with those of other studies in the literature. Aubin et al. ${ }^{(12)}$ showed that the majority ( $84 \%$ ) of their abstinent patients gained weight, whereas $16 \%$ lost weight. In the present study, those proportions were $78.9 \%$ and $15.5 \%$, respectively, and $5.6 \%$ of our patients maintained their baseline weight.

It is known that some of the drugs prescribed for smoking cessation can promote weight changes.

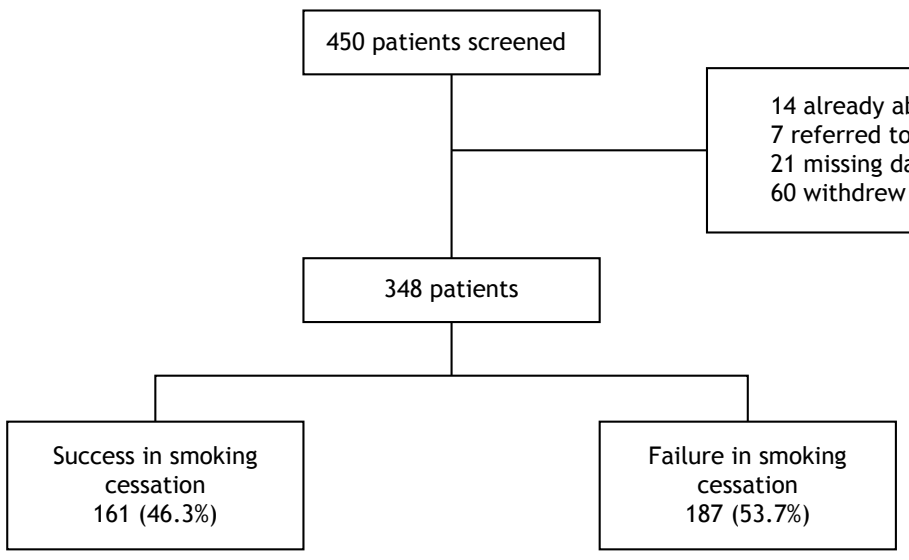

Figure 1. Flowchart of patients included in the study. 
Table 1. Demographic characteristics of the sample, by treatment outcome and weight-change group. ${ }^{\mathrm{a}}$

\begin{tabular}{|c|c|c|c|c|c|c|}
\hline \multirow[t]{2}{*}{ Variable } & \multicolumn{3}{|c|}{$\begin{array}{l}\text { Treatment success } \\
\qquad(\mathrm{n}=161)\end{array}$} & \multicolumn{3}{|c|}{$\begin{array}{l}\text { Treatment failure } \\
\text { (n }=187)\end{array}$} \\
\hline & $\begin{array}{l}\text { NoChange } \\
(n=104)\end{array}$ & $\begin{array}{l}\text { Change } \\
(n=57)\end{array}$ & p & $\begin{array}{l}\text { NoChange } \\
(n=172)\end{array}$ & $\begin{array}{l}\text { Change } \\
(\mathrm{n}=15)\end{array}$ & $\mathbf{p}$ \\
\hline Female gender & $70(67.3)$ & 41 (71.9) & 0.596 & $121(70.3)$ & $13(86.7)$ & 0.239 \\
\hline$<50$ years of age & $73(70.2)$ & $31(54.4)$ & 0.058 & $112(65.1)$ & $4(26.7)$ & 0.050 \\
\hline$\geq 11$ years of schooling & $9(9.1)$ & $3(5.3)$ & 0.538 & $18(10.7)$ & $0(0.0)$ & 0.367 \\
\hline Pack-years & $36[20-50]$ & $35[26-57]$ & 0.482 & $43[28-60]$ & $40[25-66]$ & 0.964 \\
\hline Treatment & & & 0.506 & & & 0.669 \\
\hline Counseling only & $8(7.7)$ & $4(7.0)$ & & $54(51.4)$ & $3(20.0)$ & \\
\hline Counseling + BUP & $78(75.0)$ & $38(66.7)$ & & $85(49.4)$ & $8(53.3)$ & \\
\hline Counseling + NRT & $4(3.8)$ & $3(5.3)$ & & $12(7.0)$ & $2(13.3)$ & \\
\hline Counseling + NOR & $5(4.8)$ & $7(12.3)$ & & $17(9.9)$ & $2(13.3)$ & \\
\hline Counseling + VAR & $9(8.7)$ & $5(8.8)$ & & $4(2.3)$ & $0(0.0)$ & \\
\hline Nicotine dependence level (FTND) & & & 0.324 & & & 0.246 \\
\hline Low & $33(31.7)$ & $13(22.8)$ & & $45(26.2)$ & $1(6.7)$ & \\
\hline Moderate & $48(46.2)$ & $26(45.6)$ & & $81(47.1)$ & $9(60.0)$ & \\
\hline High & $23(22.1)$ & $18(31.6)$ & & $46(26.7)$ & $5(33.3)$ & \\
\hline Baseline weight, kg & $71.6 \pm 15.1$ & $66.3 \pm 11.3$ & 0.022 & $68.4 \pm 15.3$ & $66.9 \pm 13.2$ & 0.725 \\
\hline Final weight, kg & $72.5 \pm 15.0$ & $72.0 \pm 12.1$ & 0.842 & $68.1 \pm 15.4$ & $71.5 \pm 13.6$ & 0.410 \\
\hline Baseline $\mathrm{BMI}, \mathrm{kg} / \mathrm{m}^{2}$ & $26.9 \pm 5.5$ & $25.7 \pm 4.4$ & 0.172 & $26.6 \pm 5.8$ & $26.8 \pm 3.9$ & 0.908 \\
\hline Final $\mathrm{BMI}, \mathrm{kg} / \mathrm{m}^{2}$ & $27.3 \pm 5.5$ & $27.9 \pm 4.6$ & 0.518 & $26.5 \pm 5.8$ & $28.6 \pm 4.0$ & 0.196 \\
\hline Delta BMI, kg/m² & $0.39 \pm 0.57$ & $2.21 \pm 0.79$ & $<0.001$ & $-0.11 \pm 0.65$ & $1.85 \pm 0.65$ & $<0.001$ \\
\hline
\end{tabular}

NoChange: weight unchanged or variation of no more than $5 \%$ in relation to the baseline weight; Change: weight gain of more than 5\%; BUP: bupropion; NRT: nicotine replacement therapy; NOR: nortriptyline; VAR: varenicline; FTND: Fagerström Test for Nicotine Dependence (score); and BMI: body mass index. ${ }^{a}$ Data are presented as mean $\pm \mathrm{SD}$, median [interquartile range], or $\mathrm{n}(\%)$.

Table 2. Distribution by weight-change category and treatment outcome among patients undergoing smoking cessation treatment $(\mathrm{N}=348)$.

\begin{tabular}{lccc}
\multicolumn{1}{c}{ Category } & \% change from baseline weight & $\begin{array}{c}\text { Success } \\
\text { (n }=161)\end{array}$ & $\begin{array}{c}\text { Failure } \\
\text { (n }=187) \\
\text { n (\%) }\end{array}$ \\
1-weight loss & $\mathbf{n}(\%)$ & $1 \%(0.5)$ \\
2-weight loss & 9.990 to 5.000 & $1(0.6)$ & $7(3.7)$ \\
3-weight loss & 4.990 to 0.001 & $24(14.9)$ & $72(38.5)^{*}$ \\
4-weight maintained & 0 & $9(5.6)$ & $23(12.3)^{*}$ \\
5-weight gain & $>0.001$ to 4.990 & $70(43.5)$ & $69(36.9)$ \\
6-weight gain & 5.000 to 9.990 & $39(24.2)$ & $13(7.0)^{*}$ \\
7-weight gain & $\geq 10.000$ & $18(11.2)$ & $2(1.1)^{*}$ \\
\hline
\end{tabular}

$* \mathrm{p} \leq 0.05$.

Bupropion is widely used for slimming as well as for smoking cessation. (19) Although nortriptyline is associated with weight gain when used to treat depression, ${ }^{(24)}$ its specific role in weight changes when used in smoking cessation treatment has not been fully tested. However, we found no significant differences among the pharmacological treatment arms in terms of weight changes. Aubin et al. ${ }^{(12)}$ reported similar findings in a study comparing the use of nicotine replacement therapy, bupropion, varenicline, and no pharmacotherapy.

The factors that have been associated with weight gain after smoking cessation include male gender, a higher level of nicotine dependence, and advanced age. (22) There have also been studies showing that being $<55$ years of age and having a lower SES are significant risk factors for weight gain after smoking cessation. ${ }^{(25)}$ Discrepancies across studies are likely related to differences in the length of the follow-up period.

On average, smokers weigh less than do nonsmokers. The proportion of smokers who are overweight or obese in a given population is reflective of the dietary habits in the respective country or region. Many smokers are already overweight or even have class III obesity when they attempt to quit smoking. Smoking is especially common among individuals who are preparing to undergo bariatric procedures. In a previous study conducted at our facility, ${ }^{(7)}$ the relationship between class III obesity and smoking was evaluated, and 
Table 3. Univariate analysis and multivariate Poisson regression of risk factors associated with a weight gain of more than $5 \%$ in relation to the baseline weight among the patients in whom the treatment was successful $(n=161)$.

\begin{tabular}{|c|c|c|c|c|}
\hline Variable & Crude RR (95\% CI) & $\mathbf{p}$ & Adjusted RR* (95\% CI) & $\mathbf{p}$ \\
\hline Female gender & $1.15(0.65-2.06)$ & 0.63 & $1.15(0.63-2.11)$ & 0.64 \\
\hline$<50$ years of age & $1.53(0.91-2.58)$ & 0.11 & $1.63(0.94-2.83)$ & 0.081 \\
\hline$\geq 11$ years of schooling & $0.67(0.21-2.13)$ & 0.49 & $0.72(0.22-2.36)$ & 0.59 \\
\hline Pack-years & $1.00(0.99-1.01)$ & 0.66 & $1.01(0.99-1.02)$ & 0.41 \\
\hline Comorbidities & $1.15(0.64-2.08)$ & 0.63 & $1.24(0.66-2.32)$ & 0.51 \\
\hline \multicolumn{5}{|l|}{ Treatment } \\
\hline Counseling & 1 & & 1 & \\
\hline Counseling + BUP & $0.98(0.35-2.75)$ & 0.97 & $0.93(0.33-2.62)$ & 0.89 \\
\hline Counseling + NRT & $1.29(0.29-5.75)$ & 0.74 & $1.36(0.30-6.18)$ & 0.69 \\
\hline Counseling + NOR & $1.75(0.51-5.98)$ & 0.37 & $1.25(0.36-4.37)$ & 0.73 \\
\hline Counseling + VAR & $1.07(0.29-3.99)$ & 0.92 & $0.99(0.26-3.71)$ & 0.98 \\
\hline \multicolumn{5}{|l|}{ Nicotine dependence (FTND) } \\
\hline Low & 1 & & 1 & \\
\hline Moderate & $1.24(0.64-2.42)$ & 0.52 & $1.15(0.58-2.28)$ & 0.69 \\
\hline High & $1.53(0.76-3.17)$ & 0.23 & $1.49(0.71-3.13)$ & 0.29 \\
\hline Baseline weight & $0.98(0.96-1.00)$ & 0.06 & $0.98(0.96-1.01)$ & 0.12 \\
\hline Baseline BMI, kg/m² & $0.97(0.91-1.03)$ & 0.27 & $0.98(0.92-1.04)$ & 0.41 \\
\hline$<24$ & 1 & & 1 & \\
\hline $25-30$ & $0.77(0.43-1.41)$ & 0.40 & $0.97(0.51-1.84)$ & 0.93 \\
\hline$>30$ & $0.66(0.30-1.47)$ & 0.31 & $0.70(0.31-1.61)$ & 0.40 \\
\hline Medical visits attended (n) & $1.08(1.01-1.15)$ & 0.02 & $1.05(0.88-1.26)$ & 0.56 \\
\hline
\end{tabular}

RR: relative risk; FTND: Fagerström Test for Nicotine Dependence (score); BUP: bupropion; NRT: nicotine replacement therapy; NOR: nortriptyline; VAR: varenicline; and BMI: body mass index. *Adjusted for gender, age, level of nicotine dependence (FTND score), treatment, number of visits attended, and baseline weight.

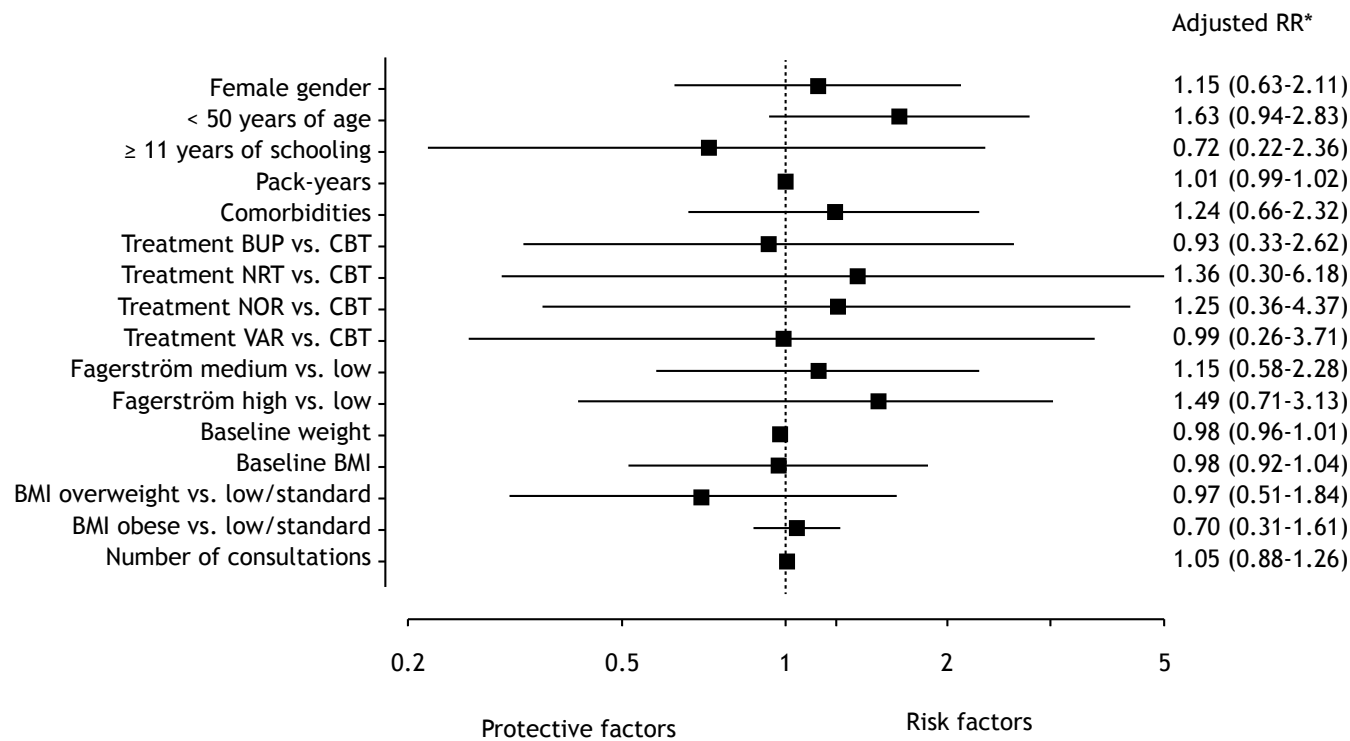

Figure 2. Forest plot of risk and protective factors for significant weight gain, adjusted for gender, age, and level of nicotine dependence (Fagerström Test of Nicotine Dependence), treatment, and follow-up. RR: relative risk; BUP: bupropion; CBT: cognitive behavioral therapy; NRT: nicotine replacement therapy; NOR: nortriptyline; VAR: varenicline; and BMI: body mass index. *Logistic regression model adjusted for gender, age, level of nicotine dependence (Fagerström Test for Nicotine Dependence score), treatment, and follow-up.

patients with class III obesity were found to be two times more likely to be a smoker than were those with lower BMIs. ${ }^{(7)}$ Those findings might be a consequence of various overlapping risk behaviors, because smokers are typically less physically active and prefer a less healthy diet, as well as consuming greater quantities of alcohol, in comparison with their non-smoking counterparts. In a subsequent study, involving 536 individuals with class III obesity, smoking was found to correlate positively with BMI, waist circumference, and percentage of body fat among the male patients with class III obesity. ${ }^{(9)}$ 
Although our findings confirm previously published results, our study adds some innovative information. To our knowledge, this is the first paper to use $\mathrm{NNH}$ calculation, a simple technique, to determine the number of treated patients needed in order to detect one with a significant weight change. The fact that we calculated an $\mathrm{NNH}$ of 3.6 means that for every 3.6 people treated, only one will show a weight gain of more than $5 \%$, whereas 2.4 will maintain their baseline weight or even lose a small proportion. The dissemination of our findings could be useful for encouraging smokers to quit. Patients should be informed that weight gain is not a significant problem in the majority of the cases. ${ }^{(24)}$ The benefits of quitting smoking outweigh any potential risks related to weight gain. Patients should also be informed that systemic arterial hypertension and type 2 diabetes mellitus, as collateral effects of weight gain-often mentioned by patients as major concerns-are uncommon, and that the benefits of quitting by far offset the consequences of weight gain related to smoking cessation. ${ }^{(26,27)}$ Nevertheless, in our sample, $11 \%$ of the patients in whom treatment success was achieved showed weight gains that could be harmful to their health (more than $10 \%$ in relation to the baseline weight). Of the patients in whom the treatment failed, only $1.1 \%$ showed such weight gains.

This study has a number of strengths. Because we employed a real-world prospective cohort design, our findings reflect the routine scenario of smoking cessation treatment at outpatient clinics in Brazil. Our sample is representative of the patients treated via the Brazilian Unified Health Care System. Another positive point is that we managed to perform biochemical verification of smoking withdrawal in all cases, despite the long follow-up period. All patients had to purchase their own medication, which could be an indicator of good adherence to the treatment and of a strong motivation to try to complete the task of quitting smoking. Another strength is that we expressed weight change as a percentage of the baseline weight, rather than as an absolute value. This innovative strategy was implemented in order to prevent erroneous interpretations. To avoid measurement errors, ${ }^{(14,28)}$ body weights were verified by a health care professional.

Our study has some limitations. The high proportion of patients treated with bupropion could have introduced a bias. However, after adjusting for several factors, we found that treatment with bupropion had no significant influence on the results. In terms of the treatment received, the patients in whom treatment success was achieved were comparable to those in whom the treatment failed. However, when we stratified the patients by weight-change group (NoChange and Change), we detected differences in the two groups that were controlled by the multivariate Poisson regression. Another limitation is that we did not evaluate possible modifications in physical activity or lifestyle. The patients might have gained weight because of lifestyle changes, such as becoming more sedentary, or might have lost weight because they started engaging in regular physical activity. In addition, patients who exercised could have increased their muscle mass, with a consequent increase in weight, which could be better evaluated by bioimpedance. Unfortunately, when we started this study, we did not have access to the equipment necessary in order to assess body composition or to determine the proportional distribution of lean and fat mass in each body segment. In the multivariate analysis, we adjusted for the possible bias of using drugs that can affect the appetite. Because this was a real-world study, the patients were not randomized to the various treatments, which could represent a bias related to patients selecting the medications on the basis of price. However, that reflects what happens in daily practice: patients do not receive medication for free. Because our findings are in keeping with those of other studies in the literature, ${ }^{(27,29)}$ we are confident that these limitations did not have a significant influence on our results.

The idea that weight gain after smoking cessation can be insignificant when specific measures for weight control are taken should be widely disseminated. Health care professionals, especially those working at primary health care clinics or smoking cessation treatment centers, should use this information as a tool to emphasize to patients that, although there truly is a possibility of weight gain during smoking cessation treatment, such weight gain occurring in a non-negligible proportion of patients, a larger proportion of patients retain their baseline weight or even lose weight. Health care professionals should further explain that weight changes will not be a major problem if certain precautions are taken. ${ }^{(27,30,31)}$ They should transmit to the smoker the idea that it is possible to quit smoking without a great risk of weight gain or of the specific comorbidities usually associated with obesity, such as systemic arterial hypertension and diabetes mellitus. ${ }^{(29)}$ This strategy could help motivated smokers overcome barriers and encourage them to give up the habit. It could also be useful in addressing undecided smokers who are concerned about possible weight gain.

\section{REFERENCES}

1. World Health Organization. WHO Report on the Global Tobacco Epidemic, 2013. Enforcing bans on tobacco advertising, promotion and sponsorship. Geneva: World Health Organization; 2013.

2. Ekpu VU, Brown AK. The Economic Impact of Smoking and of Reducing Smoking Prevalence: Review of Evidence. Tob Use Insights. 2015;8:1-35. https://doi.org/10.4137/TUI.S15628

3. Bernal RTI, Iser BPM, Malta DC, Claro RM. Surveillance System for Risk and Protective Factors for Chronic Diseases by Telephone

Survey (Vigitel): changes in weighting methodology. Epidemiol Serv Saude. 2017;26(4):701-712. https://doi.org/10.5123/S167949742017000400003

4. Komiyama M, Wada H, Ura S, Yamakage H, Satoh-Asahara N Shimatsu $A$, et al. Analysis of factors that determine weight gain during smoking cessation therapy. PLoS One. 2013;8(8):e72010. https://doi.org/10.1371/journal.pone.0072010

5. Lycett $D$, Munafò $M$, Johnstone $E$, Murphy $M$, Aveyard $P$. 
Associations between weight change over 8 years and baseline body mass index in a cohort of continuing and quitting smokers. Addiction. 2011;106(1):188-96. https://doi.org/10.1111/j.13600443.2010.03136.x

6. Taniguchi $\mathrm{C}$, Tanaka H, Oze I, Ito H, Saka H, Tachibana K, et al. Factors associated with weight gain after smoking cessation therapy in Japan. Nurs Res. 2013;62(6):414-21. https://doi.org/10.1097/ NNR.0000000000000000

7. Chatkin R, Mottin CC, Chatkin JM. Smoking among morbidly obese patients. BMC Pulm Med. 2010;10:61. https://doi.org/10.1186/14712466-10-61

8. Pisinger $C$, Jorgensen $T$. Weight concerns and smoking in a general population: the Inter99 study. Prev Med. 2007;44(4):283-9. https:// doi.org/10.1016/j.ypmed.2006.11.014

9. Chatkin R, Chatkin JM, Spanemberg L, Casagrande D, Wagner M, Mottin C. Smoking is associated with more abdominal fat in morbidly obese patients. PLoS One. 2015;10(5):e0126146. https:// doi.org/10.1371/journal.pone.0126146

10. Harris KH, Zopey M, Friedman TC. Metabolic effects of smoking cessation. Nat Rev Endocrinol. 2016;12(5):299-308. https://doi. org/10.1038/nrendo.2016.32

11. Gonseth S, Jacot-Sadowski I, Diethelm PA, Barras V, Cornuz J. The tobacco industry's past role in weight control related to smoking. Eur J Public Health. 2012;22(2):234-7. https://doi.org/10.1093/eurpub/ ckr023

12. Aubin HJ, Farley A, Lycett D, Lahmek P, Aveyard P. Weight gain in smokers after quitting cigarettes: meta-analysis. BMJ. 2012;345:e4439. https://doi.org/10.1136/bmj.e4439

13. Filozof C, Fernández Pinilla MC, Fernández-Cruz A. Smoking cessation and weight gain. Obes Rev. 2004;5(2):95-103. https://doi. org/10.1111/j.1467-789X.2004.00131.x

14. Krukowski RA, Bursac Z, Little MA, Klesges RC. The Relationship between Body Mass Index and Post-Cessation Weight Gain in the Year after Quitting Smoking: A Cross-Sectional Study. PLoS One. 2016;11(3):e0151290. https://doi.org/10.1371/journal.pone.0151290

15. Alberg AJ, Carter CL, Carpenter MJ. Weight gain as an impediment to cigarette smoking cessation: a lingering problem in need of solutions. Prev Med. 2007:44(4):296-7. https://doi.org/10.1016/j. ypmed.2007.01.001

16. Kmetova A, Kralikova E, Stepankova L, Zvolska K, Blaha M, Sticha $M$, et al. Factors associated with weight changes in successful quitters participating in a smoking cessation program. Addict Behav. 2014;39(1):239-45. https://doi.org/10.1016/j.addbeh.2013.10.010

17. Sherrill-Mittleman D, Klesges RC, Massey V, Vander Weg MW, DeBon M. Relationship between smoking status and body weight in a military population of young adults. Addict Behav. 2009;34(4):4002. https://doi.org/10.1016/j.addbeh.2008.11.015

18. Clark MM, Hurt RD, Croghan IT, Patten CA, Novotny P, Sloan JA, et al. The prevalence of weight concerns in a smoking abstinence clinical trial. Addict Behav. 2006;31(7):1144-52. https://doi.org/10.1016/j. addbeh.2005.08.011
19. Stevens J, Truesdale KP, McClain JE, Cai J. The definition of weight maintenance. Int J Obes (Lond). 2006;30(3):391-9. https://doi. org/10.1038/sj.ijo.0803175

20. Heatherton TF, Kozlowski LT, Frecker RC, Fagerström KO. The Fagerström Test for Nicotine Dependence: a revision of the Fagerström Tolerance Questionnaire. Br J Addict. 1991;86(9):111927. https://doi.org/10.1111/j.1360-0443.1991.tb01879.x

21. Zhong $Y$, Rosengren A, Fu M, Welin L, Welin C, Caidahl K, et al Secular changes in cardiovascular risk factors in Swedish 50-year-old men over a 50-year period: The study of men born in 1913, 1923 1933, 1943, 1953 and 1963. Eur J Prev Cardiol. 2017;24(6):612-620. https://doi.org/10.1177/2047487316676905

22. Prod'hom S, Locatelli I, Giraudon K, Marques-Vidal P, Clair C, Bize $\mathrm{R}$, et al. Predictors of weight change in sedentary smokers receiving a standard smoking cessation intervention. Nicotine Tob Res. 2013;15(5):910-6. https://doi.org/10.1093/ntr/nts217

23. Tian J, Venn A, Otahal P, Gall S. The association between quitting smoking and weight gain: a systematic review and meta-analysis of prospective cohort studies. Obes Rev. 2016;16(10):883-901. https:// doi.org/10.1111/obr.12304

24. Zoli M, Picciotto MR. Nicotinic regulation of energy homeostasis Nicotine Tob Res. 2012;14(11):1270-90. https://doi.org/10.1093/ntr/ nts159

25. Audrain-McGovern J, Benowitz NL. Cigarette smoking, nicotine and body weight. Clin Pharmacol Ther. 2011;90(1):164-8. https://doi org/10.1038/clpt.2011.105

26. Tonstad S. Weight gain does not attenuate cardiovascular benefits of smoking cessation. Evid Based Med. 2014;19(1):25. https://doi. org/10.1136/eb-2013-101350

27. Yeh HC, Duncan BB, Schmidt MI, Wang NY, Brancati FL. Smoking, smoking cessation, and risk for type 2 diabetes mellitus: a cohort study. Ann Intern Med. 2010;152(1):10-7. https://doi. org/10.7326/0003-4819-152-1-201001050-00005

28. Veldheer S, Yingst J, Zhu J, Foulds J. Ten-year weight gain in smokers who quit, smokers who continued smoking and never smokers in the United States, NHANES 2003-2012. Int J Obes (Lond). 2015;39(12):1727-32. https://doi.org/10.1038/ijo.2015.127

29. Clair C, Rigotti NA, Porneala B, Fox CS, D'Agostino RB, Pencina $M J$, et al. Association of smoking cessation and weight change with cardiovascular disease among adults with and without diabetes. JAMA. 2013;309(10):1014-21. https://doi.org/10.1001/ jama.2013.1644

30. Chinn S, Jarvis D, Melotti R, Luczynska C, Ackermann-Liebrich U, Antó JM, et al. Smoking cessation, lung function, and weight gain: a follow-up study. Lancet. 2005;365(9471):1629-35; discussion 16001. https://doi.org/10.1016/S0140-6736(05)66511-7

31. Pednekar MS, Hakama M, Hebert JR, Gupta PC. Association of body mass index with all-cause and cause-specific mortality: finding from a prospective cohort study in Mumbai (Bombay), India. Int $J$ Epidemiol. 2008;37(3):524-35. https://doi.org/10.1093/ije/dyn001 